\title{
Experimental study on flexural behaviour of inorganic polymer concrete beams reinforced
}

\author{
with basalt rebar \\ Xiaochun Fan ${ }^{\mathrm{a}}$, Mingzhong Zhang, ${ }^{\mathrm{b}, *}$ \\ a School of Civil Engineering and Architecture, Wuhan University of Technology, Wuhan 430070, \\ China \\ ${ }^{\mathrm{b}}$ Advanced and Innovative Materials (AIM) Group, Department of Civil, Environmental and \\ Geomatic Engineering, University College London, London WC1E 6BT, UK
}

\begin{abstract}
Corrosion of reinforcing steel and the severe degradation of mechanical properties with temperature and fire conditions are the weakest points of steel-reinforced concrete structures and fibre reinforced polymer (FRP) system, respectively. In this paper, the basalt reinforced inorganic polymer concrete (IPC) beam which combines the specific characteristics of IPC and basalt reinforcement such as good corrosion resistance and fire resistance was proposed. The inorganic polymer binder was made of fly ash, ground granulated blast-furnace slag and alkaline activating solution. The mechanical properties of IPC were measured and compared with those of reference ordinary Portland cement (OPC) concrete. The flexural behaviour of basalt reinforced IPC beam was investigated and compared to control steel-reinforced OPC concrete beam. The measured ultimate flexural capacity of basalt reinforced IPC beam was compared with the predicted value obtained using the guidelines for FRP-reinforced OPC concrete beam. Results indicated that the elastic modulus of IPC was very close to OPC, while the compressive strength and flexural strength of IPC were around $80 \%$ of those of OPC. The IPC beam reinforced with basalt rebar exhibited a two-stage load-midspan deflection response that was different from control concrete beam due to the different mechanical properties of basalt and steel rebars. The crack patterns in basalt reinforced IPC beam were found to be similar to control beam, however, the maximum crack width of basalt reinforced beam was approximately 2 times that of control beam. The guidelines for FRP-reinforced concrete beam were adequate for predicting the flexural strength of basalt reinforced IPC beams.
\end{abstract}

Keywords: A. Polymer (textile) fibre; B. Mechanical properties; B. Microstructures; B. Strength; Geopolymers

\section{Introduction}

Concrete is the most widely used man-made material in the world. The sustainability has become an increasingly important characteristic for concrete infrastructure, as the manufacture of Portland cement accounts for a significant proportion of raw material consumption and nearly $7 \%$ of global $\mathrm{CO}_{2}$ emissions [1]. Inorganic polymers, also called geopolymers, are conventionally produced by synthesizing pozzolanic compounds or aluminosilicate source materials with highly alkaline hydroxide and/or alkaline silicate. Over the last two decades, inorganic polymer concretes (IPC) have emerged as novel engineering materials with the potential to become a substantial element in an environmentally sustainable construction and building products industry [2,3]. Industrial by-products, such as fly ash (FA) and ground granulated blast-furnace slag (GGBFS) are commonly used as the source of IPC due to the low cost and wide availability of these materials. It has been shown that compared to ordinary Portland cement (OPC) concrete, IPC has many attractive properties, such as good fire resistance, good resistance to chloride penetration, acid attack, freeze-thaw cycles, etc. and can help reduce embodied energy and carbon footprint by up to 80\% [4-6].

\footnotetext{
* Corresponding author. Tel: +44 (0)20 7679 7299. E-mail address: mingzhong.zhang@ucl.ac.uk (M. Zhang)
} 
Corrosion of reinforcing steel is the leading cause of deterioration of reinforced concrete (RC) structures. In recent years, an increasing attention has been paid towards the replacement of traditional steel bars with fibre reinforced polymer (FRP) as internal concrete reinforcement to solve the problem of rebar corrosion in RC structures. The most commonly used FRP reinforcing bars for concrete structures are made from glass (GFRP), carbon (CFRP) and aramid (AFRP). However, the performance of GRRP and AFRP would be significantly affected by the alkaline environment within concrete [7]. CFRP reinforcing bars are too expensive to be implemented in normal civil engineering structures [8]. A new type of reinforcing bars made from basalt fibre (BFRP) has recently gathered attention as an alternative to other FRPs because of its cost effectiveness, ease of manufacture, high temperature resistance, freeze-thaw performance and good resistance to vibration and impact loading, corrosion and acids [9-12]. In addition, BFRP has better durability in alkaline conditions compared to GFRP [13]. Because of these outstanding characteristics, BFRP fibres have been used either as internal reinforcement for new concrete structures or as external strengthening for existing concrete structures [14].

Over the past few years, many efforts have been made to investigate the mechanical behaviour of steel- and FRP-reinforced inorganic polymer (geopolymer) concrete, and BFRP reinforced concrete in order to offer a solid theoretical basis for the use of geopolymer concrete and BFRP in concrete structures. With respect to the interaction between reinforcement and geopolymer concrete, Songpiriyakij et al. [15] experimentally studied the bonding strength between the embedded steel rebar and substrate geopolymer concrete made of fly ash, rice husk and bark ash and silica fume, and showed that the bond strength of rebar and geopolymer was slightly higher than that of control OPC concrete (1.05-1.12 times). Sarker [16] used the beam-end test method to measure the bond strength of low calcium fly ash-based geopolymer concrete with deformed steel rebars and compared with the equivalent OPC concrete system. The geopolymer concrete was observed to have higher bond strength than OPC concrete, which was attributed to the higher splitting tensile strength of geopolymer concrete relative to OPC concrete of the same compressive strength. Castel and Foster [17] carried out the standard RILEM pull-out test to investigate the bond between geopolymer and deformed and smooth steel rebars. The used geopolymer binder was composed of $85.2 \%$ of low calcium fly ash and $14.8 \%$ of GGBFS. The 28-day bond strength and the overall bond stress-slip behaviour of the geopolymer concrete were found to be similar to those of OPC concrete. Menna et al. [18] studied the flexural behaviour of reinforced geopolymer concrete beams strengthened with high strength steel cord and CFRP to evaluate the effectiveness of strengthening. Results indicated that geopolymer matrix provided a very good adhesion to concrete substrate and to reinforcement. With respect to BFRP reinforced concrete, Tomlinson and Fam [19] evaluated the flexural and shear performances of concrete beams reinforced with BFRP rebar and stirrups, and found that the beams with BFRP had significantly higher strengths than control steel-reinforced counterparts with the same reinforcement ratio. Ge et al. [20] carried out a series of experiments including tensile test, standard pull-out test of BFRP bars and static flexural test on hybrid concrete beams reinforced with BFRP bars and steel bars, and observed that the bond strength between BFRP rebar and concrete is similar to that of steel rebar and concrete. These previous studies have shown that the systems of steel rebar and geopolymer concrete, and BFRP rebar and OPC concrete have a similar bond behaviour and mechanical performance to control steel-reinforced OPC concrete, which leads to the idea in this study of combing BFRP rebar and IPC (geopolymer concrete) in a composite system to improve the durability and sustainability of concrete structures. According to authors' knowledge, the mechanical behaviour of IPC beam reinforced with BFRP reinforcement has not been extensively investigated elsewhere.

In this work, the mechanical properties including compressive strength, flexural strength and elastic modulus of IPC are studied and compared to reference OPC concrete. The inorganic polymer binder is composed of both fly ash and GGBFS. Afterwards, the flexural behaviour of IPC beam reinforced with BFRP rebar in terms of ultimate flexural strength and cracking patterns and development is investigated in detail and compared with that of control steel-reinforced OPC concrete 
beam to understand the failure mechanisms of BFRP reinforced IPC beam. A comparison between the theoretical previsions of the flexural behaviour of the tested beams calculated according to the recommendations for FRP-reinforced OPC concrete beam and experimental data for BFRP reinforced IPC beam was carried out to estimate whether the guidelines for FRP-reinforced concrete system are adequate for predicting the flexural strength of IPC beams with BFRP reinforcement.

\section{Materials and Methods}

\subsection{Inorganic polymer concrete}

The inorganic polymer concrete used for experiments was made of a mixture of inorganic polymer binder composed of FA, GGBFS and alkaline activating solution, fine and coarse aggregates. FA and GGBFS used in this study were produced by Qingshan Power Station and Wuhan Iron and Steel Company Limited in Wuhan in Hubei Province of China, respectively. The chemical compositions of FA and GGBFS are given in Table 1. The scanning electron microscope (SEM) images of FA and GGBFS morphology are shown in Fig. 1. The alkaline activating solution was obtained by dissolving solid sodium hydroxide $(\mathrm{NaOH})$ into sodium silicate $\left(\mathrm{Na}_{2} \mathrm{SiO}_{3}\right)$ solution with the $\mathrm{Na}_{2} \mathrm{SiO}_{3} / \mathrm{NaOH}$ ratio of 1.53. Fifteen series of inorganic polymer binder were prepared and tested in order to determine the optimal composition of the mixture accounting for both early-age properties and durability, which was presented in detail in a previous work [11]. The medium-sized sand with fineness modulus of 2.72 was used as fine aggregate. The coarse aggregate was $13 \mathrm{~mm}$ nominal size crushed stone. The particle size distributions of fine and coarse aggregates are presented in Tables 2 and 3, respectively.

The mix proportion of raw materials in inorganic polymer concrete is given in Table 4 . The fine and coarse aggregates were firstly mixed for $2 \mathrm{~min}$. Afterwards, the inorganic polymer binder was mixed together with fine and coarse aggregates for about 3 min followed by a gradual addition of free water. The inorganic polymer concrete was then placed in the moulds and compacted using a poker vibrator. The concrete specimens were prepared for compressive and flexural tests.

Table 1 Chemical compositions of fly ash and GGBFS (wt.\%)

Table 2 Particle size distribution of fine aggregate in inorganic polymer concrete

Table 3 Particle size distribution of coarse aggregate in inorganic polymer concrete

Table 4 Mix proportion of raw materials in inorganic polymer concrete $\left(\mathrm{kg} / \mathrm{m}^{3}\right)$

Fig. 1 SEM images: (a) fly ash; (b) ground granulated blast-furnace slag

\subsection{Basalt rebar}

Fig. 2 shows the used BFRP reinforcing bar for inorganic polymer concrete beams. It was supplied by Shenzhen Academy of Aerospace Technology. According to the manufacturer the Young's modulus, yield strength and ultimate tensile strength of BFRP rebar are $50 \mathrm{GPa}, 600 \mathrm{MPa}$ and 650 $1000 \mathrm{MPa}$, respectively. In order to study the mechanical behaviour of IPC beams reinforced with basalt rebar, it is necessary to examine the stress-strain relationship of basalt rebar. In this work, the uniaxial tensile tests were performed on five basalt rebars using a servo-hydraulic testing machine with a capacity of $600 \mathrm{kN}$ according to GB/T5224-2014 [21]. The experimental setup for uniaxial tensile tests is shown in Fig. 3. Load was applied to the rebar through displacement control at a rate of $0.08 \mathrm{~mm} / \mathrm{s}$ until failure. The stress-strain relationship of basalt rebars under uniaxial tension is shown in Fig. 4. For each stress-strain curve, it can be seen that there exists an initial elastic region followed by a small hardening region until ultimate failure, although the yielding point is not obvious. The yield strength of these five basalt rebars is found to be $659 \mathrm{MPa}, 549 \mathrm{MPa}, 660 \mathrm{MPa}, 657 \mathrm{MPa}$ and $600 \mathrm{MPa}$, respectively. The tensile strength of them is $678 \mathrm{MPa}, 569 \mathrm{MPa}, 681 \mathrm{MPa}, 673 \mathrm{MPa}$ and $610 \mathrm{MPa}$, respectively. 
Fig. 2 Basalt FRP bar used for inorganic polymer concrete beams

Fig. 3 Setup for uniaxial tensile test of basalt FRP bar

Fig. 4 Stress-strain relationship of basalt FRP bars

\subsection{Testing program}

Uniaxial compressive strength was measured at 3, 7 and 28 days on $150 \mathrm{~mm}$ concrete cube based on GB/T 50081-2002 [22]. The modulus of elasticity and flexural strength were measured at 28 days on rectangular concrete prism $\left(100 \times 100 \times 300 \mathrm{~mm}^{3}\right.$ and $100 \times 100 \times 400 \mathrm{~mm}^{3}$, respectively $)$ according to GB/T 50081-2002 [22] and JTGE30-2005 [23], respectively.

To investigate the flexural behaviour of reinforced concrete system, two inorganic polymer concrete beams reinforced with BFRP rebar, referred to as IPCB1 and IPCB2, with size of $120 \mathrm{~mm}$ width $\times 200 \mathrm{~mm}$ height $\times 2000 \mathrm{~mm}$ length were prepared and cast for 28 days. For the purpose of comparison, two ordinary Portland concrete beams of the same size reinforced with steel rebars with a diameter of $14 \mathrm{~mm}$ and nominal yield strength of $360 \mathrm{MPa}$ were cast and considered as control concrete beams, which are hereafter named as OPCB1 and OPCB2. The diameter of BFRP rebar used in this work is determined according to the method of equal-strength substitution. As such, steel rebar is replaced with BFRP rebar, while the latter has the same strength, i.e., $d_{1}^{2} f_{f y, 1}=d_{2}^{2} f_{f y, 2}$, in which $d_{1}$ and $d_{2}$ are the diameters of steel and BFRP rebars, and $f_{f y, 1}$ and $f_{f y, 2}$ denote their nominal yield strength, respectively. The diameter of BFRP rebar obtained using the method of equal-strength substitution is $10.8 \mathrm{~mm}$. However, the rebar in $10.8 \mathrm{~mm}$ diameter is not available in the specifications for rebar. Therefore, the $12 \mathrm{~mm}$ diameter BFRP rebar was chosen and used for IPCB1 and IPCB2. It should be noted that this would result in an approximately $18 \%$ greater contribution of reinforcement to IPC beams than that to OPC beams. Fig. 5 depicts the geometric and loading details of the beam specimens. All the beams were tested as simply supported members, over a clear span of $1.9 \mathrm{~m}$ and loaded up to failure under a four-point bending configuration with a constant moment region of 0.6 $\mathrm{m}$ across the midspan according to GB/T 50152-2012 [24]. The load was applied through a $5000 \mathrm{kN}$ hydraulic actuator. The entire test and measurement was carried out under displacement control. The crosshead displacement rate was $0.5 \mathrm{~mm} / \mathrm{min}$.

During the tests, three vertical linear displacement gauges were used to measure and determine the average midspan deflection of the beam at each loading stage. Thus, the corresponding forcedeflection curve can be obtained, which is presented in the following sections. Five horizontal linear strain gauges were placed on one side of the specimen to record displacements across the midspan at different depths. Displacements at supports were measured by linear variable differential transformer (LVDT). One strain gauge was bonded to each rebar at its midspan to record the strain of rebar under loading. An automatic data acquisition system was utilized to monitor loading. The IPCB1 beam specimen before and after loading is shown in Fig. 6.

Fig. 5 Four-point bending configuration for basalt reinforced inorganic polymer concrete beams

Fig. 6 Basalt reinforced inorganic polymer concrete beam specimen: (a) before loading; (b) after loading

\section{Experimental results and discussion}

\subsection{Mechanical characteristics}

Fig. 7 shows the time evolution of compressive strength of OPC concrete and IPC. Three specimens were used to measure the compressive strength. As expected, the compressive strength goes up with increasing curing age. For both OPC concrete and IPC, the compressive strength at 3 days is $48 \%$ of 
that at 28 days, and the 7-day compressive strength is around $66 \%$ of 28 -day compressive strength. A very similar trend in the increase in compressive strength can be observed for OPC concrete and IPC, although the compressive strength of IPC at each curing age is approximately $80 \%$ of that of OPC concrete.

Table 5 shows the flexural strength and elastic modulus of OPC concrete and IPC, which were measured using three and six specimens, respectively. All measures were performed on specimens after curing of 28 days. It can be seen that the flexural strength of IPC is about $80 \%$ of that of OPC concrete, while the elastic moduli of them are very close.

\section{Fig. 7 Time evolution of compressive strength of concrete}

Table 5 Flexural strength and elastic modulus of concrete

\subsection{Load-deflection response at midspan}

Fig. 8 depicts the measured load-deflection response at midspan for the tested beams. Values of loads and midspan deflections corresponding to the first cracking, the yielding of reinforcing basalt/steel rebars and the final bending failure of the beam are summarized in Table 6. As seen in Fig. 8, two control beams OPCB1 and OPCB2 show a very consistent three-stage load-deflection response. Taking OPCB1 as an example, concrete and internal steel reinforcing bar initially work together to resist deformation and only a small deflection can be observed. In this stage, the slope of loaddeflection curve is large, which reflects the high stiffness of the system. Once the load reaches around $24 \mathrm{kN}$ at a midspan deflection of $1.5 \mathrm{~mm}$, the first cracking of beam appears and a loss of stiffness occurs due to the tensile failure of concrete within the maximum bending moment region. As a consequence, the slope of load-deflection curve starts to decrease and the tensile steel reinforcing bar has to bear the load alone. At a load value of $96 \mathrm{kN}$, another decrease in the slope of load-deflection curve starts to happen, which can be ascribed to the yielding of the tensile steel rebar corresponding to $10.5 \mathrm{~mm}$ of midspan deflection. Afterwards, there exists a rapid increase in deflection from 10.5 $\mathrm{mm}$ to $22 \mathrm{~mm}$, whereas the load value does not change much, just increasing by $8 \mathrm{kN}$. In the meantime, the flexural cracks in terms of both number and size show a significant increase with increasing deformation until the collapse of the beam as a result of concrete crushing in the compression zone. The ultimate load and midspan deflection are found to be $104 \mathrm{kN}$ and $15 \mathrm{~mm}$, respectively. The control beam OPCB2 exhibits a very similar trend in terms of load-deflection response with OPCB1. The first cracking happens at a load value of $28 \mathrm{kN}$ followed by a loss of stiffness until the yielding of reinforcing steel bar occurs at a load of $112 \mathrm{kN}$, which is a little bit higher than yielding load of OPCB1. After yielding, the stiffness of the beam decreases and the slope of force-deflection curve is the same as that of OPCB1, whereas the ultimate load is $116 \mathrm{kN}$ occurring at a midspan deflection of $15.7 \mathrm{~mm}$.

Unlike the control concrete beams, the load-midspan deflection curves of IPC beams only consist of two parts. The first part is very similar to that observed in control beams and the first cracking loads are close to those of control beams, followed by a significant loss of stiffness. Compared to control beams, the slopes of load-deflection curves of IPC beams in the second part are much lower, which can be associated with the lower elastic modulus of BFRP rebar in IPC beams than steel reinforcing bar in control beams and the lower volume fraction of reinforcement in IPC beams than OPC beams, as the elastic modulus of IPC is almost the same as that of OPC concrete. In addition, there does not exist an obvious yielding load prior to final failure, which is different with that detected in control beams. This can be attributed to the fact that the stress-strain curve of BFRP rebar in IPC beams is almost linear elastic, since the yield point is not obvious (as seen in Fig. 4) and the hardening region prior to ultimate failure is very small. This is different with that of steel rebar in OPC concrete beams. As a result, there shows a steady increase in midspan deflection until the ultimate deformation is reached. The ultimate loads of IPCB1 and IPCB2 are found to be a little bit lower in comparison to control OPC beams, which may be mainly due to the lower flexural and compressive strength of 
IPC as compared to OPC concrete, as presented above. However, the ultimate deflections of IPC beams are about 2.5 times of those of control beams.

Fig. 8 Load-deflection response at midspan for concrete beams

Table 6 Load and midspan deflection of concrete beams

\subsection{Load-strain response of concrete}

As the strain at different positions along the depth play a crucial role in the determination of load capacity of reinforced concrete beams under flexure, it is essential to measure these strains. Herein, the strains in the constant moment region of beams were obtained by using five horizontal linear strain gauges at depths of $d=20,40,100,160$ and $180 \mathrm{~mm}$ from the bottom surface at midspan, as shown in Fig. 5. The measured concrete strains of the test beams under loads of 20, 40, 60 and $80 \mathrm{kN}$ are shown in Fig. 9. It can be seen that for each beam, the strains at different depths under various loading values follow a similar trend that the upper part of the beam is in compression while the lower part is in tension. There exists a layer above the centre of beam that is subjected to neither tensile nor compressive train, i.e., the so-called neutral layer. As expected, the strains along the depth from the top to the bottom seem to be linear regardless of the level of loading, which implies that the beam cross sections remain plane during bending and the bond between concrete and reinforcing bar is perfect. All these indicate that concrete and reinforcing bar are able to work together very well to bear loads and thus the plane cross-section assumption can be used to estimate the load capacity of the beams subjected to bending in this study.

Fig. 9 Strains of concrete at different positions along the height of beams under various loads: (a) OPCB1; (b) OPCB2; (c) IPCB1 and (d) IPCB2

\subsection{Load-strain response of rebar}

Figs. 10 and 11 show the load-strain response of reinforcing bars in IPC beam and control beam, respectively. The strains were measured at five different locations: the midspan and four points which are $10 \mathrm{~cm}$ and $20 \mathrm{~cm}$ far from the supporting points, as shown in Fig. 5.

It can be seen from Fig. 8 that the change in strain of BFRP rebar against load at midspan follows a two-stage process: a short linear rise and a gradual increase. In the first stage, no cracking occurs in the beam and BFRP rebar and IPC work together to bear the tensile forces. As a result, the strain of BFRP rebar goes up linearly with the load. In the beams, the cross-sectional area of IPC in the tensile region is much larger than that of BFRP rebar, while their elastic moduli are of the same order of magnitude (the elastic moduli of IPC and BFRP rebar are $32.1 \mathrm{GPa}$ and $50 \mathrm{GPa}$, respectively), which results in a much sharper increase in the strain of BFRP rebar compared to that of IPC, as seen from the slopes of the curves in Figs. 8 and 10. Taking IPCB1 as an example, there is an increase in the strain of BFRP rebar at midspan from 0 to $648 \mathrm{~mm}$ when the flexural loading is increased from 0 to $20 \mathrm{kN}$, while the corresponding strain of IPC at midspan only increases from 0 to $206 \mathrm{~mm}$. As the load increases, the stress of concrete in the tensile region goes up and subsequently reaches the tensile strength of concrete, which gradually leads to cracking at the edge of the tensile region and stress redistribution in this region. In the second stage, the concrete cracking in the tensile region grows further and the reinforcing bars start to bear the tensile forces alone, which results in a gradual linear increase in the strain of reinforcing bars, in particular for the BFRP rebar whose elastic modulus is around 1/4 of steel rebar exhibiting a much larger deformation compared to steel rebar. The strain of BFRP rebar in IPCB is observed to be approximately four times that of steel rebar in OPCB due to the relatively lower elastic modulus, as seen in Figs. 10 and 11 that the slope of load-strain curve for IPCB is smaller than that for OPCB. This implies that at the same loading level the deflection of IPCB is larger than that of OPCB and the corresponding crack width is larger relative to OPCB leading to an even more obvious stress redistribution in the beam. In addition, at midspan the steel 
rebar behaves differently from BFRP rebar that the load-strain curve tends to be relatively horizontal before reaching the ultimate load, which is attributed to the difference in mechanical properties of steel and BFRP rebars.

As shown in Figs. 10 and 11 the load-strain curves for reinforcing bars at endpoints with distances of 10 and $20 \mathrm{~cm}$ from the supporting points consists of three stages, which is similar to the case of midspan point. The end of the first linear stage corresponds to the occurrence of concrete cracking and the initiation of stress distribution in concrete beams. The stress redistribution of reinforcing bars at endpoints occurs at load values of around $60 \mathrm{kN}$. This is much later than the midspan point, where the stress redistribution happens at a load of approximately $20 \mathrm{kN}$. Additionally, the strain of reinforcing bars at endpoints is lower than that at midspan point till the final failure of concrete beams, which indicates that prior to final failure there exists a strong bond between reinforcing bars and concrete and thus they work well together to bear the forces.

Fig. 10 Load-strain curve of basalt reinforcement in IPCB1

Fig. 11 Load-strain curve of steel reinforcement in OPCB1

\subsection{Crack patterns}

Fig. 12 shows the final crack patterns of reinforced concrete beams, IPCB1 and OPCB1, under flexural loading. The development of cracking in inorganic polymer concrete beam and control concrete beam during loading is depicted in detail in Figs. 13 and 14. The numbers in figures denote the corresponding load values to crack growth.

For control concrete beams, the first cracking occurs within the constant moment zone at load values of $24 \mathrm{kN}$ and $28 \mathrm{kN}$, respectively. As load increases, more and more cracks form and spread outward from midspan into the shear spans. At a load of around $70 \mathrm{kN}$, the inclined shear cracks occur. With further increase in load, these cracks propagate towards the compression zone of the beam near the loading point. When the imposed load on the beams approaches the ultimate load capacity, cracks spread very rapidly leading to a smaller concrete compression zone due to an upward shift of the neutral axis, which results in the crush of concrete and final failure of concrete beams in compression.

The basalt reinforced inorganic polymer concrete beams behave similarly to control concrete beams. The first cracks are noticed in the constant moment regions on IPCB1 and IPCB2 when the applied load reaches about $22 \mathrm{kN}$ and $24 \mathrm{kN}$, respectively. As the load increases, the existing cracks develop and some new flexural cracks are formed in the region between load and support. Upon further increasing the applied load, the majority of the flexural cracks develops vertically and after that inclined flexure-shear cracks begin to appear at a load of around $60 \mathrm{kN}$, which is consistent with the results of load-strain response of basalt rebar in IPC beams as shown in Fig. 10. As the load increases further, the inclined cracks progress in terms of length and width both upward toward the applied load point and horizontally along the longitudinal BFRP rebar towards the support. As a result, the effective area of concrete section in the compressive region is reduced. After additional application of load, the beams eventually fail in compression. Although the cracking loads of control concrete beams are higher than those of basalt reinforced IPC beams, however, the average deflection at the first crack formation for control beams is found to be $1.9 \mathrm{~mm}$ that is much lower than $3.9 \mathrm{~mm}$ for IPC beams. In addition, the number of cracks at failure for IPC beams seems to be larger than that for control beams. All these indicate that the basalt reinforced IPC beams have higher resistance to fracture than control concrete beams.

Fig. 12 Crack patterns of concrete beams under flexural loading: (a) IPCB1 and (b) OPCB1

Fig. 13 Crack development in OPCB2 under flexural loading 
Fig. 14 Crack development in IPCB2 under flexural loading

3.6 Comparison with theoretical previsions

Herein, a theoretical prevision of the mechanical behaviour of the tested basalt reinforced IPC beams is computed and compared with the experimental results in terms of predicted flexural capacity and failure mode. Since the performance of BFRP rebar is different from reinforcing steel bar, the guidelines for steel reinforced concrete beam may not be applicable to basalt reinforced IPC beam. In this work, the flexural capacity of IPC beams is calculated according to the recommendations of the ACI 440.1R-15 [25] guidelines for the FRP-reinforced concrete beam in conjunction with the following considerations and assumptions:

(1) The beam cross sections remain plane during the whole flexural loading process.

(2) The strength development of inorganic polymer concrete is similar with ordinary Portland cement concrete, which is described as the following equation. The elastic moduli of these two types of concrete are close to each other, as seen in Table 5.

$\left\{\begin{array}{cc}\sigma_{c}=f_{c}\left[1-\left(1-\frac{\varepsilon_{c}}{\varepsilon_{0}}\right)^{n}\right] & \varepsilon_{c} \leq \varepsilon_{0} \\ \sigma_{c}=f_{c} & \varepsilon_{0}<\varepsilon_{c} \leq \varepsilon_{c u}\end{array}\right.$

with

$\varepsilon_{0}=0.002+0.5\left(f_{c u, k}-50\right) \times 10^{-5}$

$\varepsilon_{c u}=0.0033-\left(f_{c u, k}-50\right) \times 10^{-5}$

$n=2-\frac{1}{60}\left(f_{c u, k}-50\right)$

where $\sigma_{c}$ and $\varepsilon_{c}$ denote the concrete stress and strain, respectively, $\varepsilon_{0}$ and $\varepsilon_{c u}$ represent the concrete strain corresponding to the concrete stress values of $f_{c}$ and $f_{c u, k}$, respectively.

(3) As seen in Fig. 4, the stress-strain curve of basalt rebar is almost linear elastic. For simplicity sake, it can be expressed by

$\sigma_{f}=E_{f} \varepsilon_{f}$

where $\sigma_{f}, E_{f}$ and $\varepsilon_{f}$ stand for the stress, elastic modulus and strain of basalt rebar, respectively.

(4) As the tensile strength of inorganic polymer concrete is much smaller than that of basalt rebar, therefore, this tensile strength can be ignored and the basalt reinforcement is assumed to resist the tensile stress alone.

(5) There exists a good bonding between reinforcing basalt and inorganic polymer concrete and the debonding failure of the reinforcing system would not occur prior to the ultimate flexural load. In fact, this assumption can be verified using the measured load-strain response of basalt rebar at midspan, as shown in Fig. 10.

For a basalt reinforced IPC beam, the balanced failure occurs when the compressive and tensile zones reach yielding at the same imposed load on the beam, and hence the concrete will crush and tensile basalt reinforcement will yield at the same time. In such case, the height of equivalent rectangular stress over the height of the beam is defined as the balanced relative compressive height, $\xi_{f y}$. A schematic diagram of the stress distribution over the beam's cross section for balanced failure condition is given in Fig. 15. Based on the balance and compatibility conditions, the parameters in Fig. 15 can be obtained as follows:

$$
\begin{aligned}
& x=\beta_{1} x_{\mathrm{c}}=\frac{\beta_{1} \varepsilon_{c u}}{\varepsilon_{c u}+\varepsilon_{f y}} h_{0} \\
& \alpha_{1} f_{c} b x=A_{f} f_{f y}=\rho_{f b} b h_{0} f_{f y}
\end{aligned}
$$




$$
\xi_{b f}=\frac{\beta_{1}}{1+\frac{f_{f y}}{\varepsilon_{c u} E_{f}}}
$$

where $x$ is the balanced compression height, $x_{c}$ is the real balanced compressive height, $\alpha_{1}$ and $\beta_{1}$ are the coefficients of equivalent rectangular stress and height of concrete, $\varepsilon_{c u}$ denotes the ultimate compressive strain $\left(\varepsilon_{c u}=0.0033\right), f_{f y}$ and $\varepsilon_{f y}$ stand for the nominal yield strength and corresponding yield strain of BFRP rebar, $b$ and $h_{0}$ are the width and effective height of beam's cross-section, and $\rho_{f b}$ represents the balanced reinforcement ratio of BFRP rebar, which can be expressed as

$\rho_{f b}=\alpha_{1} \beta_{1} \frac{f_{c}}{f_{f y}} \frac{\varepsilon_{c u}}{\varepsilon_{c u}+\varepsilon_{f y}}$

The real tensile stress $\left(f_{f}\right)$ of the basalt reinforcement when the crushing of inorganic polymer concrete happens can be calculated according to the following balance equations:

$$
\begin{aligned}
& \left\{\begin{array}{c}
\alpha_{1} f_{c} b x=f_{f} A_{f} \\
M=f_{c} b x\left(h_{0}-\frac{x}{2}\right)
\end{array}\right. \\
& f_{f}=E_{f} \varepsilon_{c u} \frac{h_{0}-x_{c}}{x_{c}}
\end{aligned}
$$

Combining Eqs. (7) and (8), we can get

$$
f_{f}=\left(\sqrt{\frac{\left(E_{f} \varepsilon_{c u}\right)^{2}}{4}+\frac{\alpha_{1} \beta_{1} f_{c} E_{f} \varepsilon_{c u}}{\rho_{f}}}-0.5 E_{f} \varepsilon_{c u}\right) \leq f_{f u}
$$

where $\rho_{f}$ is the reinforcement ratio of BFRP rebar in the beam, which is equal to the ratio between the cross-sectional area of BFRP rebar and the cross-sectional area of beam, i.e., $A_{f} /\left(b h_{0}\right)$.

The ultimate flexural capacity of the basalt reinforced IPC beam, $M_{u}$, can be obtained as:

$$
M_{u}=A_{f} f_{f}\left(h_{0}-\frac{x}{2}\right)
$$

with

$$
x=\frac{A_{f} f_{f}}{\alpha_{1} f_{c} b}
$$

According to Eq. (6), the theoretical value of balanced reinforcement ratio for basalt reinforced IPC beam is $0.48 \%$. While the applied reinforcement ratio in this work is $0.95 \%$, which is about 2 times the balanced reinforcement ratio. This implies that the tested basalt reinforced IPC beams would fail in compression, which is consistent with the experimental findings in terms of stress-strain curve and crack patterns. In addition, the applied reinforcement ratio is less than 3 times the balanced reinforcement ratio, which indicates that the tested basalt reinforced IPC beams can be considered as balanced-reinforced beams, as a reinforced concrete beam with a reinforcement ratio varying from 1.5 times to 3 times the balanced reinforcement ratio is generally defined as a balanced-reinforced beam. Furthermore, the theoretical ultimate flexural capacity of basalt reinforced IPC beam calculated using Eq. (10) is $87 \mathrm{kN}$, which is very close to the mean value of measured flexural capacity of the tested beams, i.e. $94 \mathrm{kN}$. The good agreement between the theoretical prediction and experimental data confirms that the design codes for FRP-reinforced concrete beam are applicable to inorganic polymer concrete beam reinforced with basalt rebar.

Fig. 15 Stress distribution over the beam's cross-section for balanced failure condition 


\section{Conclusions}

The flexural behaviour of inorganic polymer concrete (IPC) beams reinforced with basalt rebar was tested and compared with control steel-reinforced ordinary Portland concrete (OPC) beams in this study. A comparison of the experimental results with theoretical prevision of the mechanical behaviour of the tested beams according to the recommendations for the FRP-reinforced concrete beam was carried out. The following main conclusions can be drawn from the present study:

- The compressive strength of IPC with the proposed mix design at various curing age was a little bit lower than control OPC.

- The basalt reinforced IPC beam behaved differently from control steel-reinforced concrete beam in terms of load-deflection response due to the difference in mechanical behaviour between IPC and OPC, and basalt and steel reinforcement. For control beam, there existed an obvious yielding stage, while the load-deflection curve of IPC beam reinforced with basalt bar did not exhibit such stage. At the same applied load, the deflection of basalt reinforced IPC beam was around 4 times that of control beam.

- The development of cracking and crack patterns in basalt reinforced IPC beam under flexural loading was similar to control steel-reinforced OPC beam, while the maximum crack width of basalt reinforced beam was approximately 2 times that of control beam. Additionally, although the cracking load of control beam was larger than that of basalt reinforced beam, however, the corresponding crack deflection of basalt reinforced beam was around one time larger than that of control beam.

- The theoretical ultimate flexural capacity of basalt reinforced IPC beams calculated using the recommendations for the FRP-reinforced concrete beam was close to the measured ultimate flexural strength of the tested beams, which indicates that such recommendations are adequate for predicting the flexural strength of IPC beams reinforced with basalt reinforcement. In addition, the tested basalt reinforced IPC beams can be regarded as balanced-reinforcement beams.

\section{Acknowledgements}

The authors gratefully acknowledge the financial support from Wuhan University of Technology through grant number 631200321. The authors are grateful to all reviewers for their constructive comments and suggestions.

\section{References}

[1] Juenger MCG, Siddique R. Recent advances in understanding the role of supplementary cementitious materials in concrete. Cem Concr Res 2015;78:71-80.

[2] Duxson P, Fernández-Jiménez A, Provis JL, Lukey GC, Palomo A, Van Deventer JSJ. Geopolymer technology: the current state of the art. J Mater Sci 2007;42(9):2917-33.

[3] Provis JL, Van Deventer JSJ. Geopolymers: structures, processing, properties, and industrial applications, Woodhead Publishing Limited, Cambridge; 2009.

[4] Bakharev T. Resistance of geopolymer materials to acid attack. Cem Concr Res 2005;35(4):65870.

[5] Hu SG, Wang HX, Zhang GZ, Ding QJ. Bonding and abrasion resistance of geopolymeric repair material made with steel slag. Cem Concr Comp 2008;30(3):239-44.

[6] Sofi M, van Deventer JSJ, Mendis PA. Engineering properties of inorganic polymer concretes (IPCs). Cem Concr Res 2007;37:251-7.

[7] Sim K, Park C, Moon DY. Characteristics of basalt fiber as a strengthening material for concrete structures. Compos Part B 2005;36(6-7):504-12.

[8] Herwig A, Motavalli M. Axial behavior of square reinforced concrete columns strengthened with lightweight concrete elements and unbonded GFRP wrapping. J Compos Constr 2012;16(6):747-52. 
[9] Pavlovski D, Mislavsky B, Antonov A. CNG cylinder manufacturers test basalt fibre. Reinf Plast 2007;51(4):36-7, 39.

[10] Shi J, Zhu H, Wu Z, Wu G. Durability of BFRP and hybrid FRP sheets under freeze-thaw cycling. Adv Mater Res 2011;163-167:3297-300.

[11] Liu H, Lu Z, Peng Z. Test research on prestressed beam of inorganic polymer concrete. Mater Struct 2015;48:1919-30.

[12] Li W, Xu J. Mechanical properties of basalt fiber reinforced geopolymeric concrete under impact loading. Mater Sci Eng A 2009;505:178-86.

[13] Lee JJ, Song J, Kim H. (2014) Chemical stability of basalt fiber in alkaline solution. Fibres Polym 2014;15(11):2329-34.

[14] Wei B, Cao H, Song S. Environmental resistance and mechanical performance of basalt and glass fibers. Mater Sci Eng A 2010;527(18-19):4708-15.

[15] Songpiriyakij S, Pulngern T, Pungpremtrakul P, Jaturapitakkul C. Anchorage of steel bars in concrete by geopolymer paste. Mater Des 2011;32(5):3021-8.

[16] Sarker PK. Bond strength of reinforcing steel embedded in fly ash-based geopolymer concrete, Mater Struct 2001;44(5):1021-30.

[17] Castel A, Foster SJ. Bond strength between blended slag and Class F fly ash geopolymer concrete with steel reinforcement. Cem Concr Res 2015;72:48-53.

[18] Menna G, Asprone D, Ferone C, Colangelo F, Balsamo A, Prota A, Cioffi R, Manfredi G. Use of geopolymers for composite external reinforcement of $\mathrm{RC}$ members. Compos Part $\mathrm{B}$ 2013;45:1667-76.

[19] Tomlinson D, Fam A. Performance of concrete beams reinforced with basalt FRP for flexure and shear. J Compos Constr 2015;19(2):04014036.

[20] Ge W, Zhang J, Cao D, Tu Y. Flexural behaviors of hybrid concrete beams reinforced with BFRP bars and steel bars. Constr Build Mater 2015;87:28-37.

[21] Standardization Administration of China. Steel strand for prestressed concrete - GB/T 52242014. Beijing, China; 2014.

[22] Ministry of Construction of the People's Republic of China. Standard for test method of mechanical properties on ordinary concrete - GB/T 50081-2002. Beijing, China; 2003.

[23] Ministry of Transport of the People's Republic of China. Test methods of cement and concrete for highway engineering - JTGE30-2005. Beijing, China; 2005.

[24] Ministry of Housing and Urban-Rural Development of the People's Republic of China. Standard for test method of concrete structures - GB/T 50152-2012. Beijing, China; 2012.

[25] American Concrete Institute (ACI) Committee 440. Guide for the design and construction of structural concrete reinforced with fiber-reinforced polymer (FRP) bars - ACI 440.1R-15. Farmington Hills, MI. ACI; 2015. 


\section{Figures}
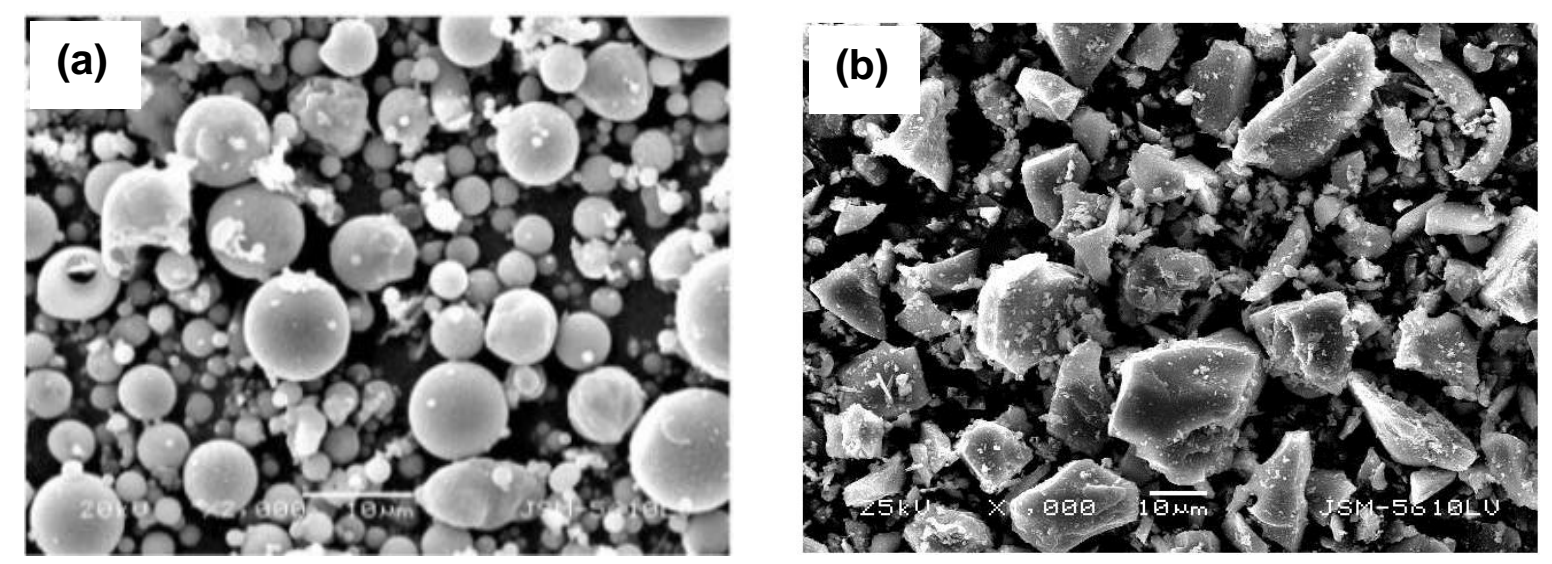

Fig. 1 SEM images: (a) fly ash; (b) ground granulated blast-furnace slag

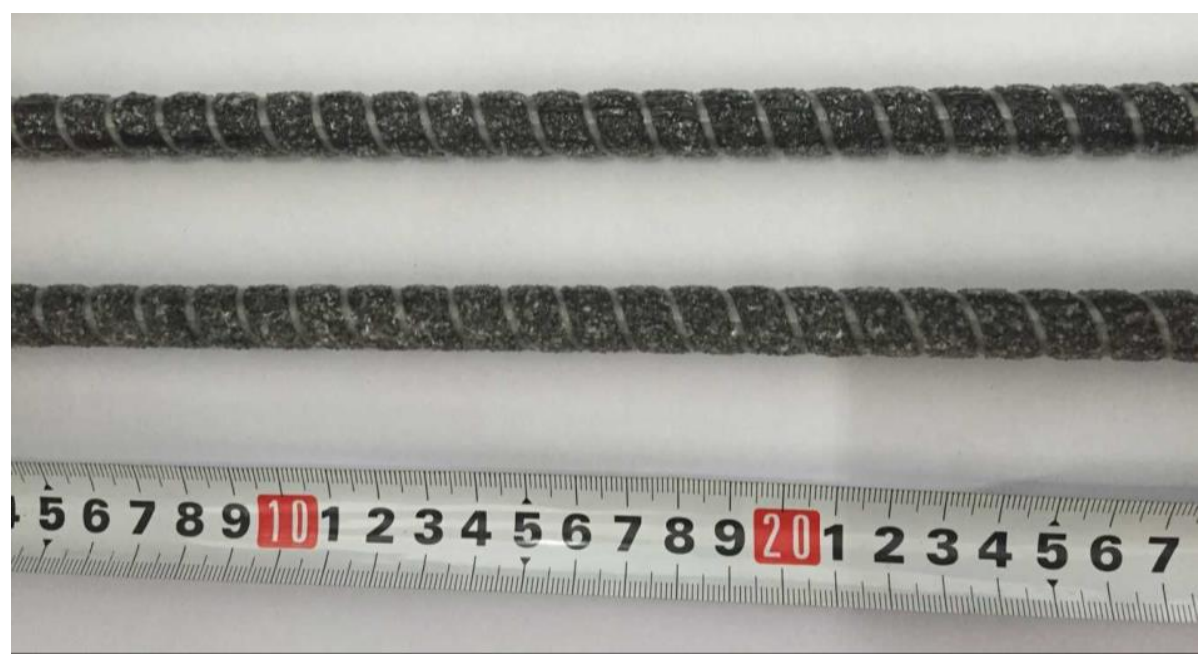

Fig. 2 Basalt FRP bar used for inorganic polymer concrete beams 


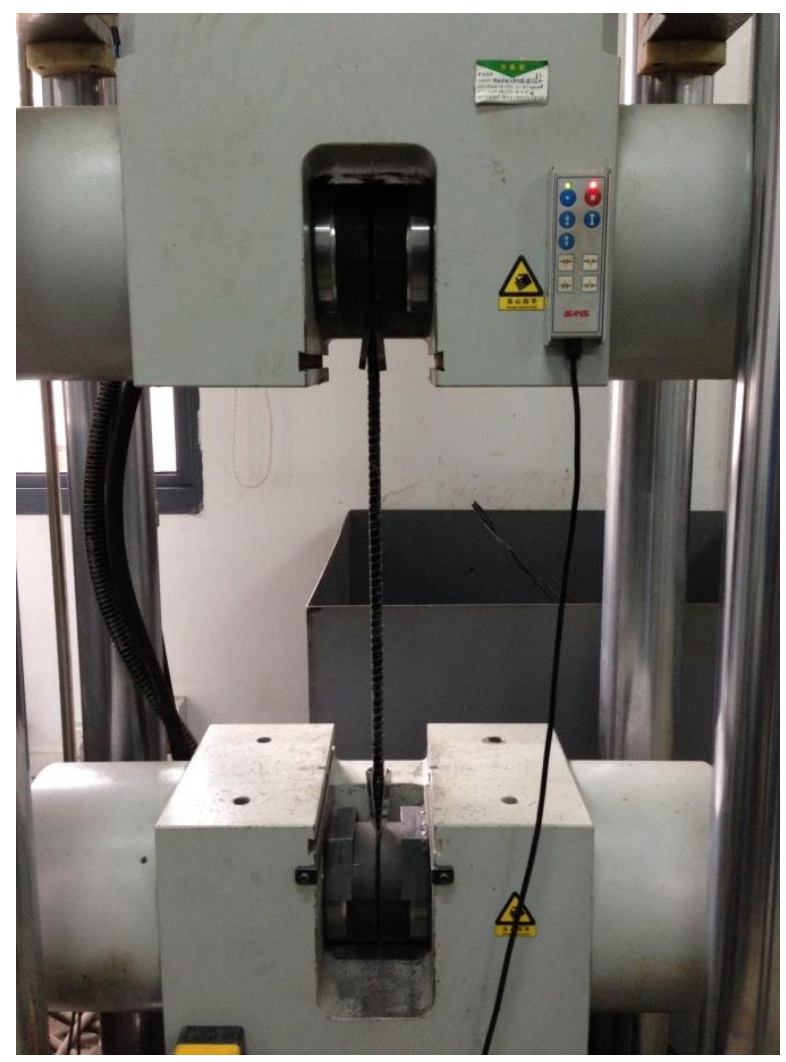

Fig. 3 Setup for uniaxial tensile test of basalt FRP bar

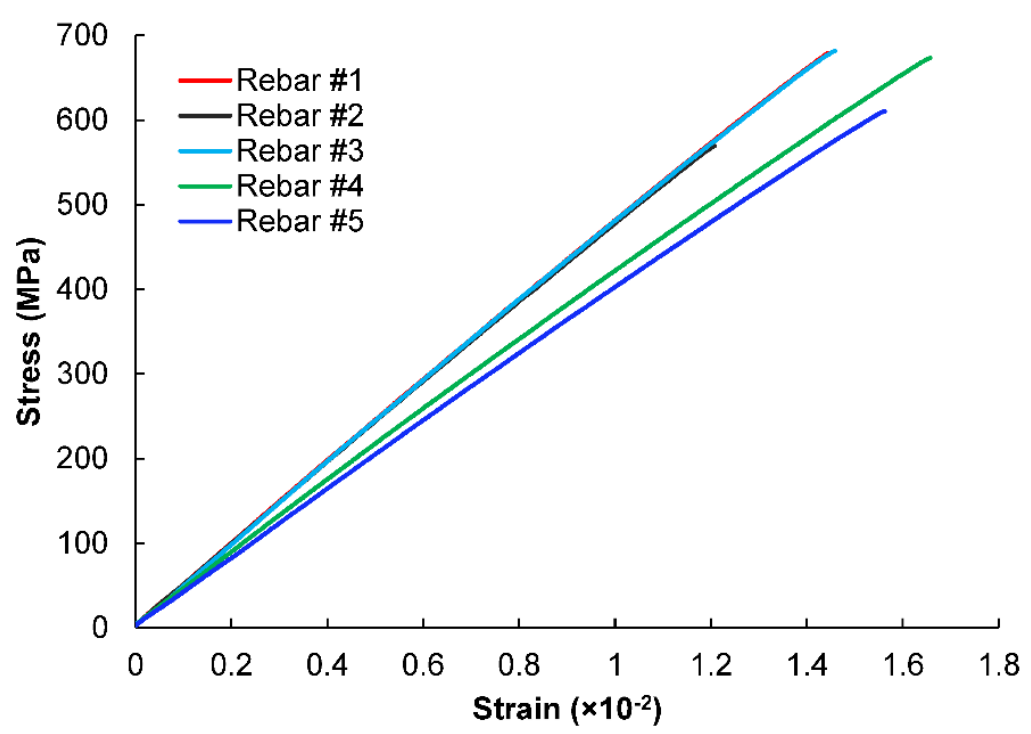

Fig. 4 Stress-strain relationship of basalt FRP bars 


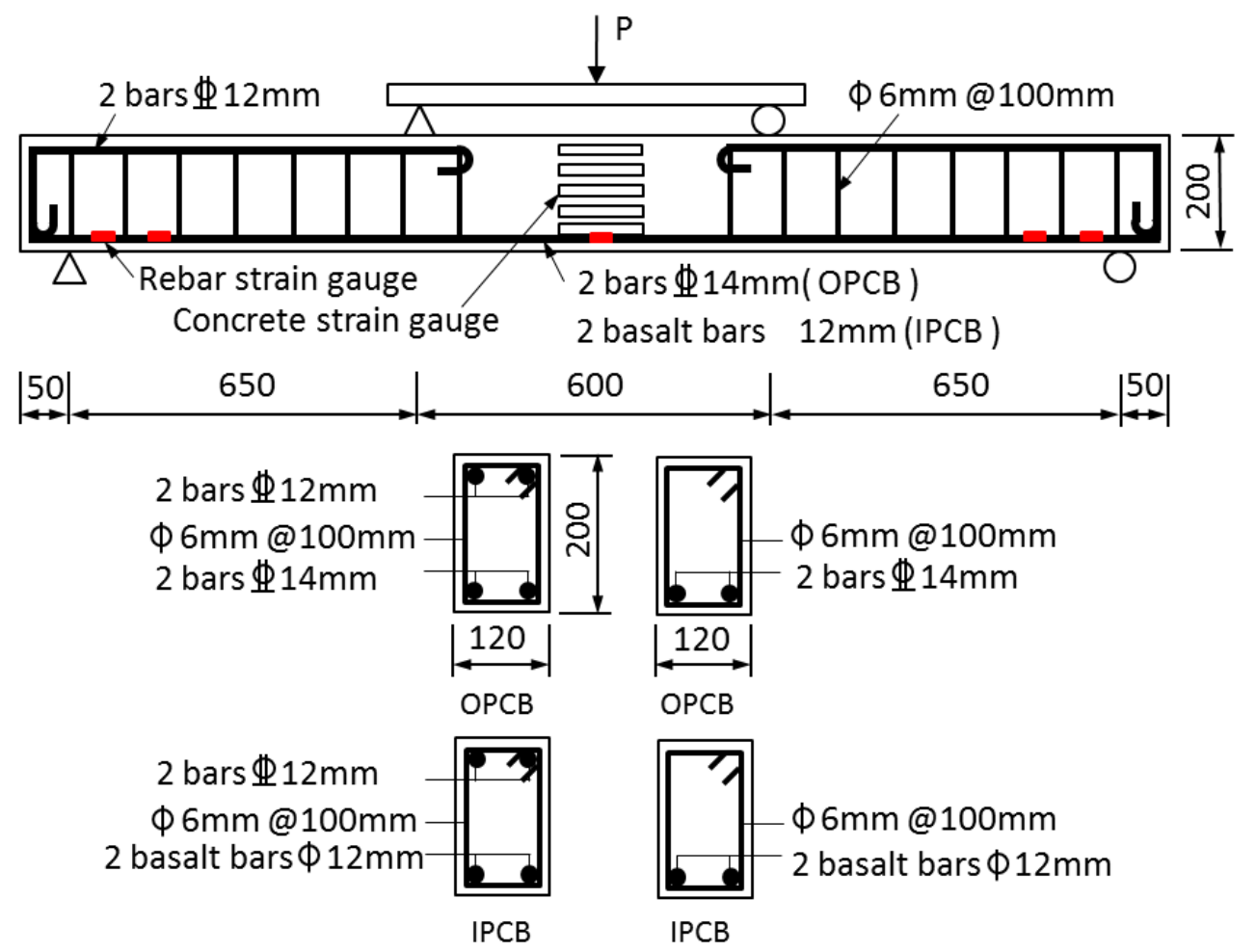

Fig. 5 Four-point bending configuration for basalt reinforced inorganic polymer concrete beams
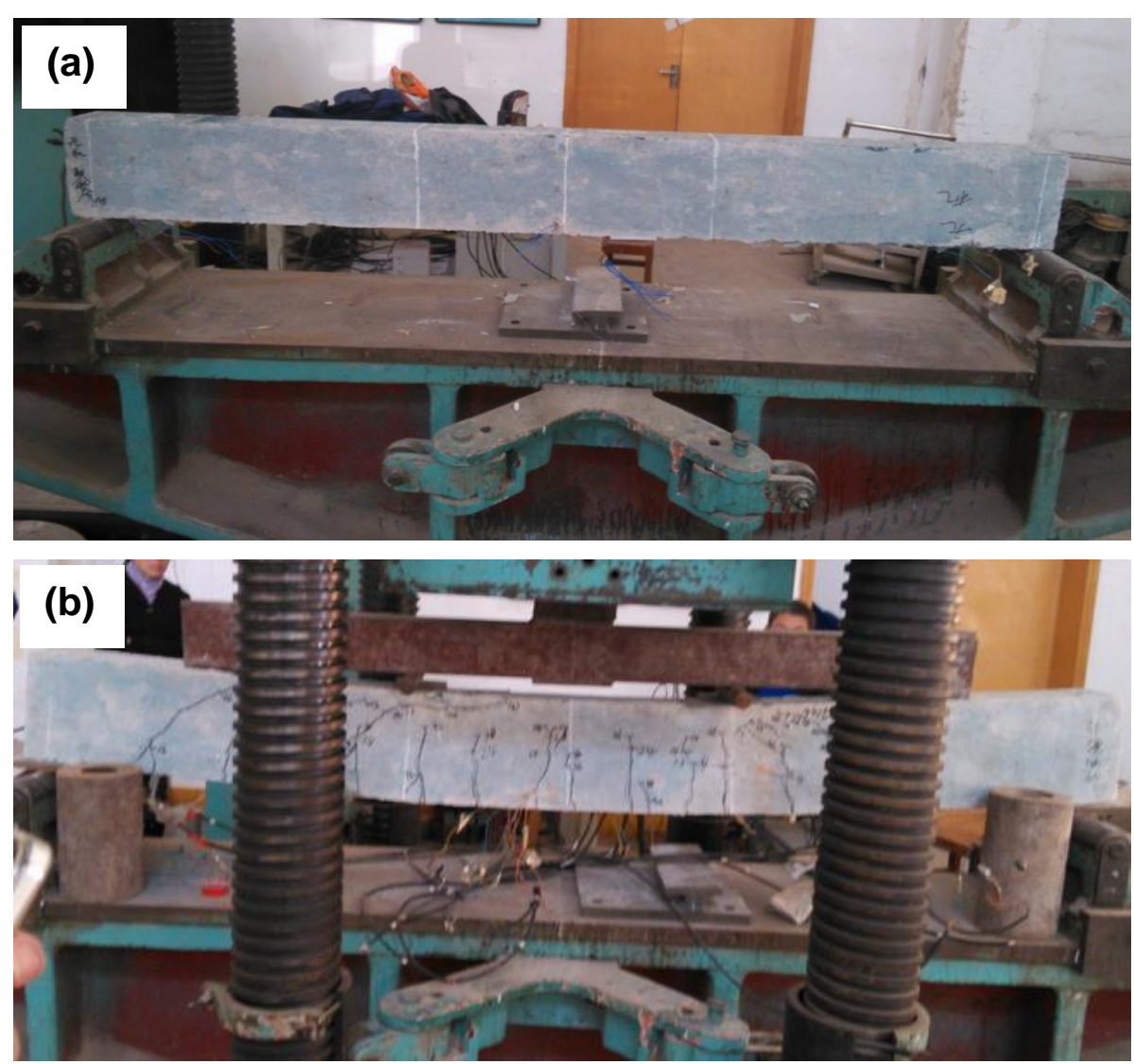

Fig. 6 Basalt reinforced inorganic polymer concrete beam specimen: (a) before loading; (b) after loading 


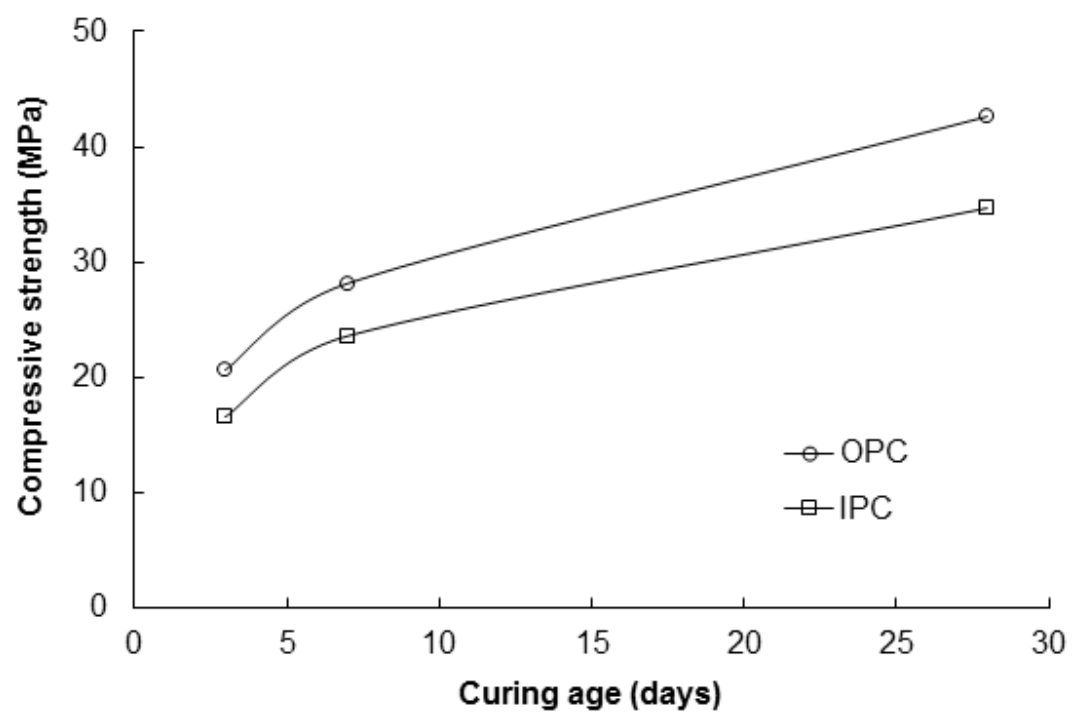

Fig. 7 Time evolution of compressive strength of concrete

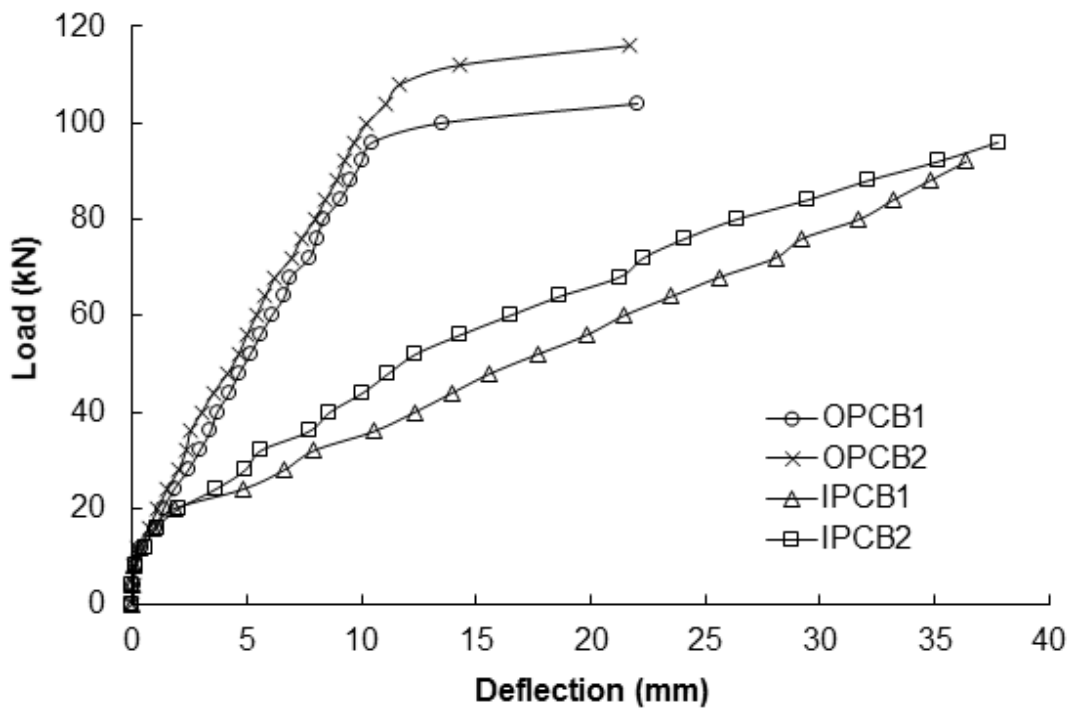

Fig. 8 Load-deflection response at midspan for concrete beams 

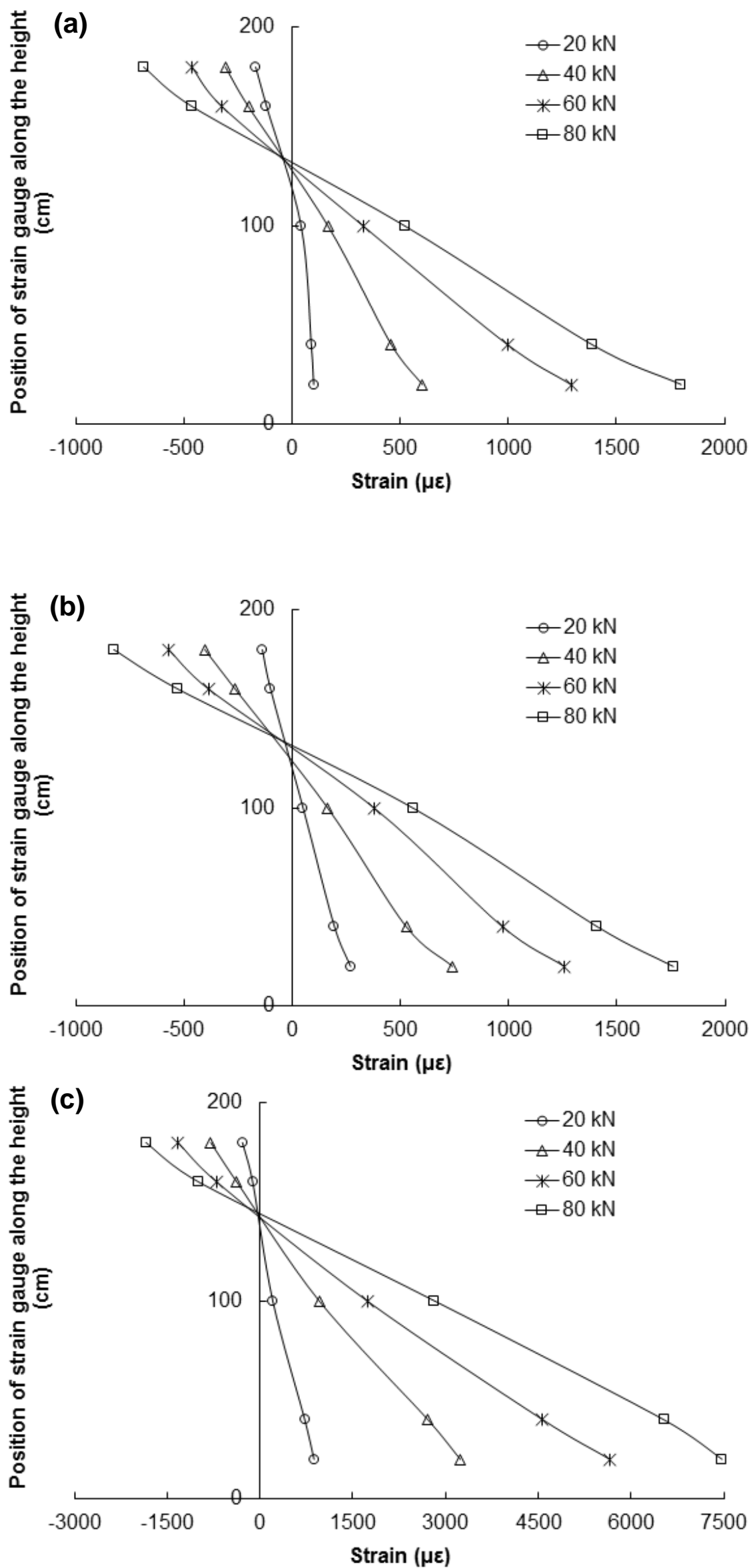


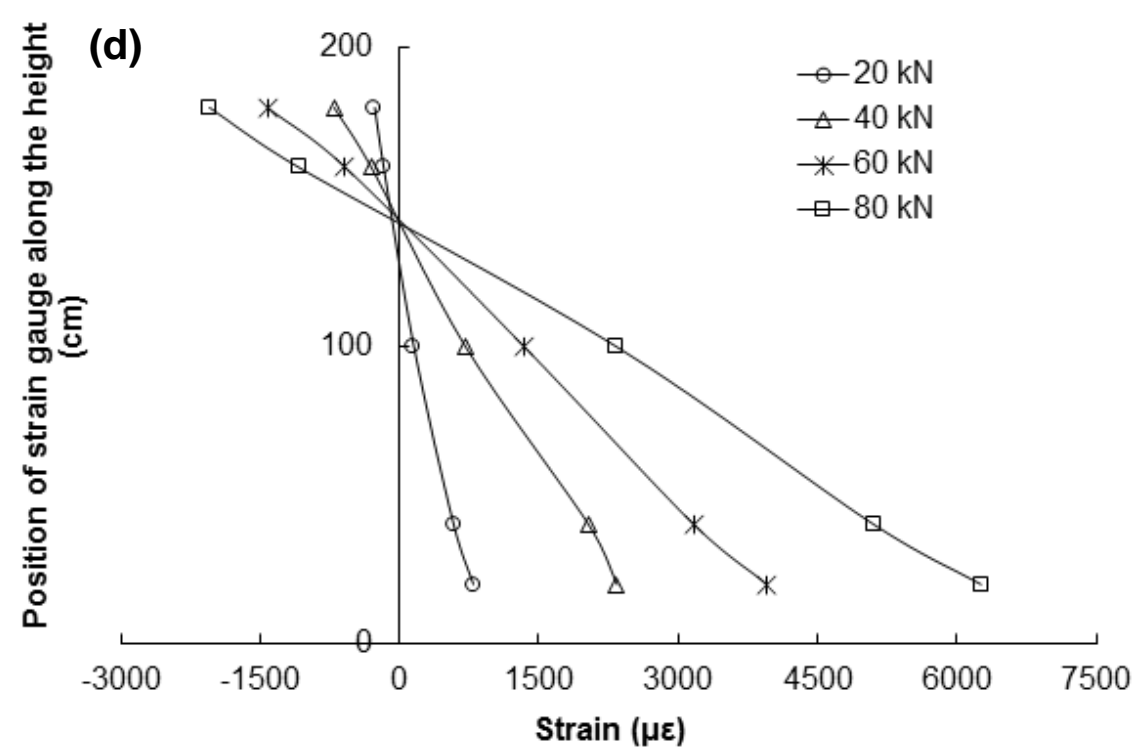

Fig. 9 Strains of concrete at different positions along the height of beams under various loads: (a) OPCB1; (b) OPCB2; (c) IPCB1 and (d) IPCB2

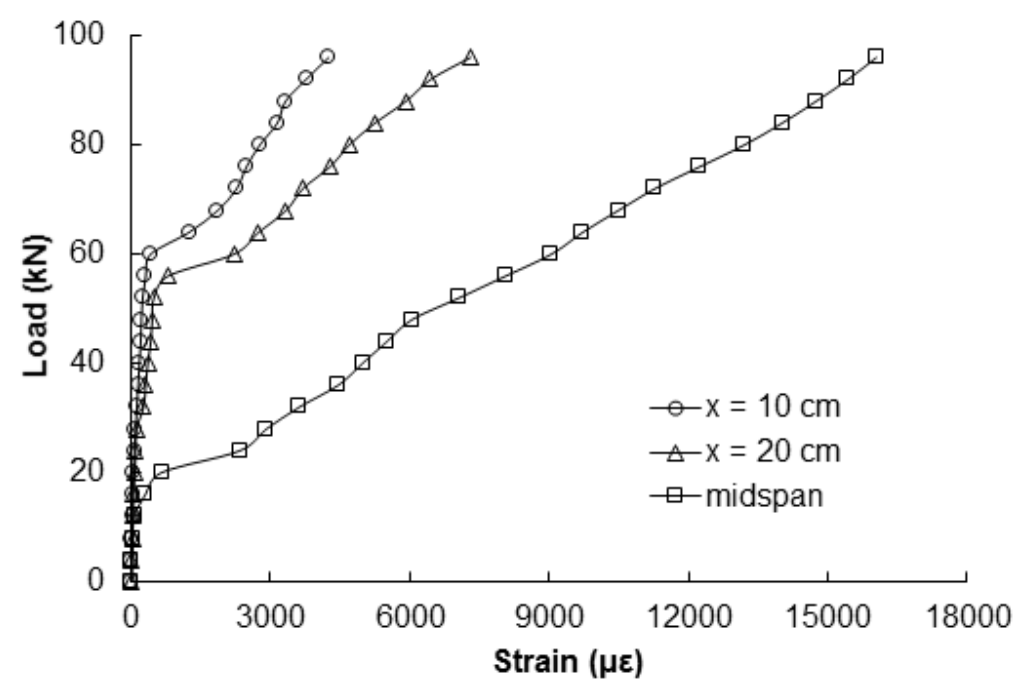

Fig. 10 Load-strain curve of basalt reinforcement in IPCB1 


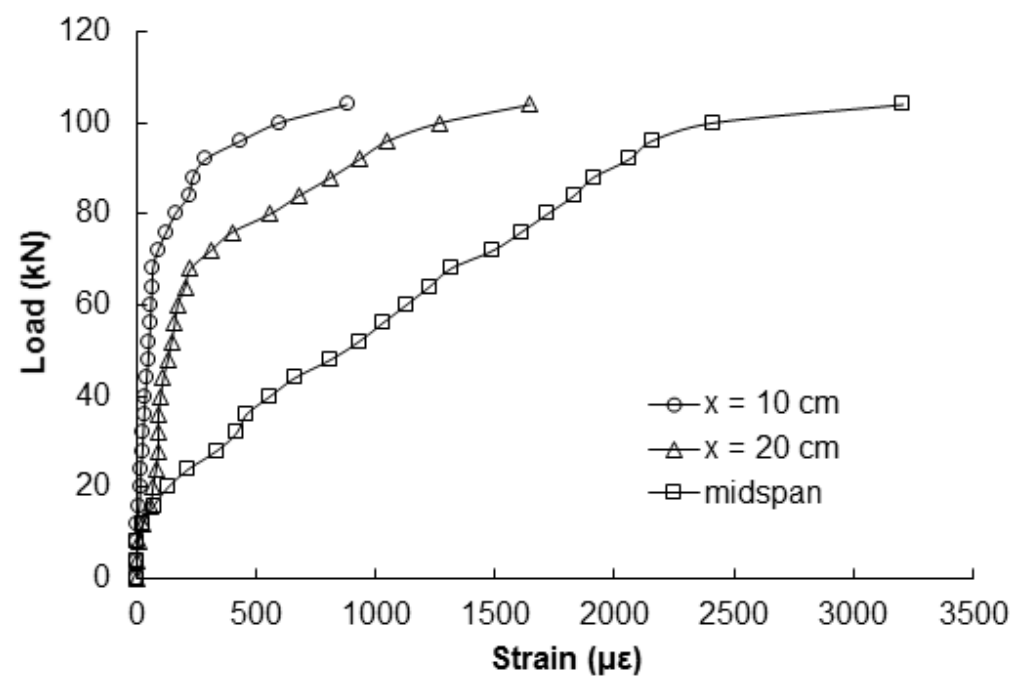

Fig. 11 Load-strain curve of steel reinforcement in OPCB1

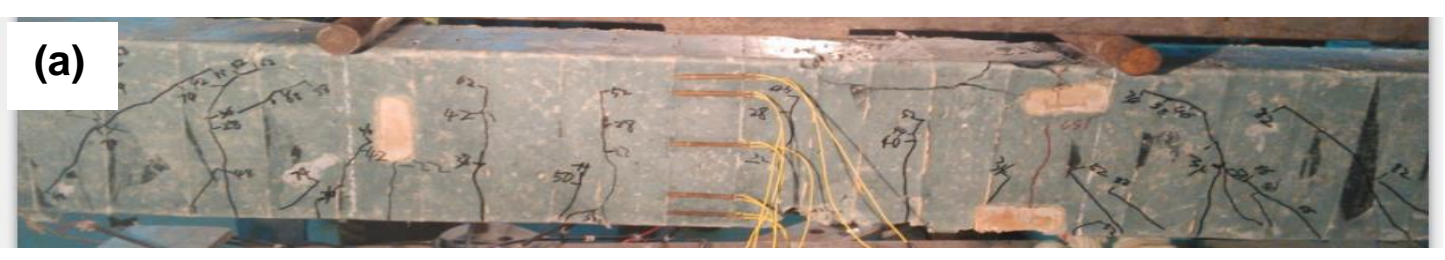

(b)

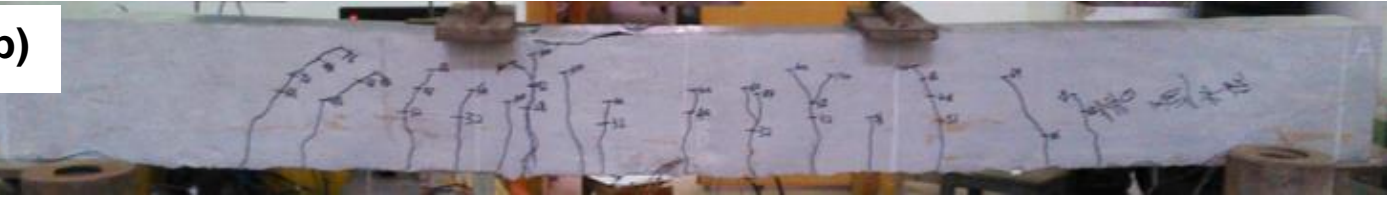

Fig. 12 Crack patterns of concrete beams under flexural loading: (a) IPCB1 and (b) OPCB1
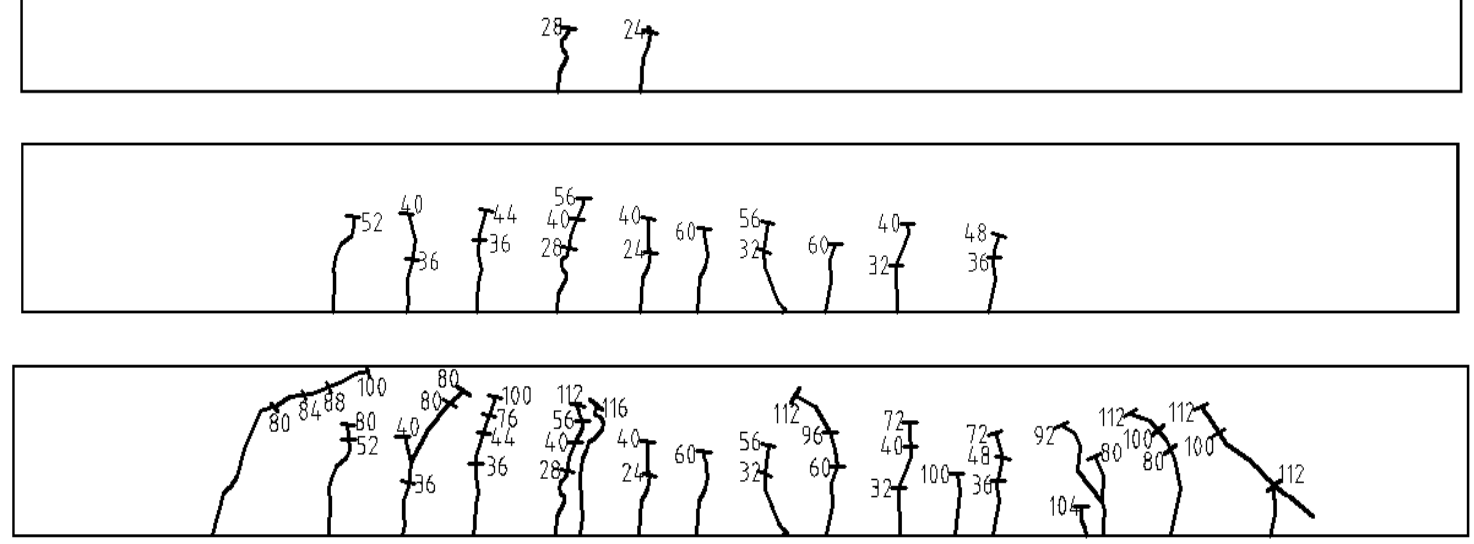

Fig. 13 Crack development in OPCB2 under flexural loading 


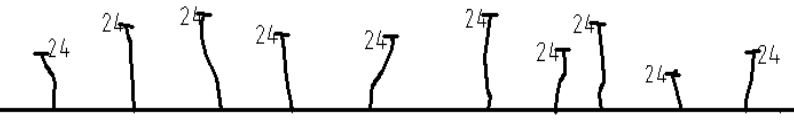
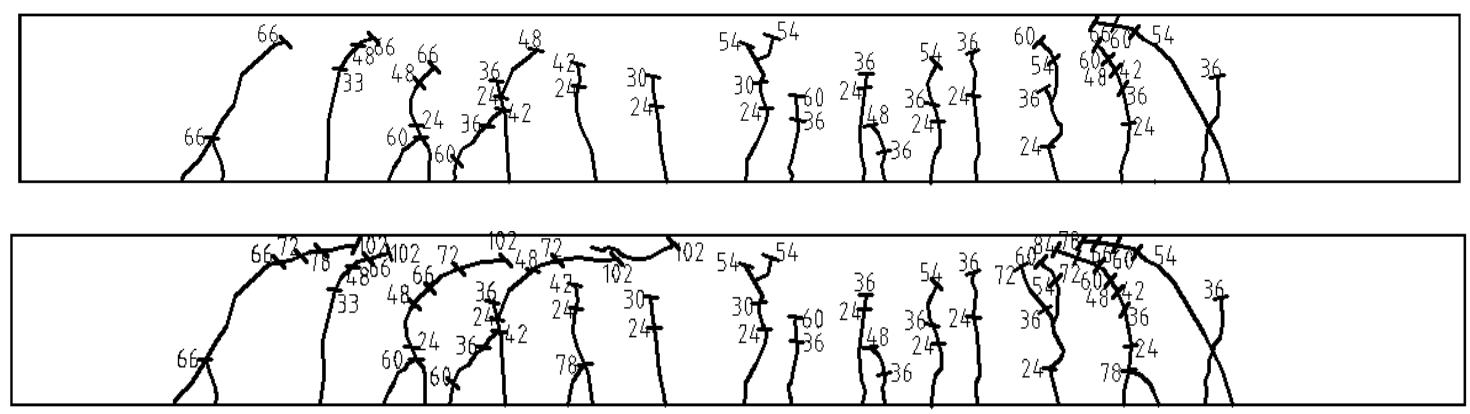

Fig. 14 Crack development in IPCB2 under flexural loading
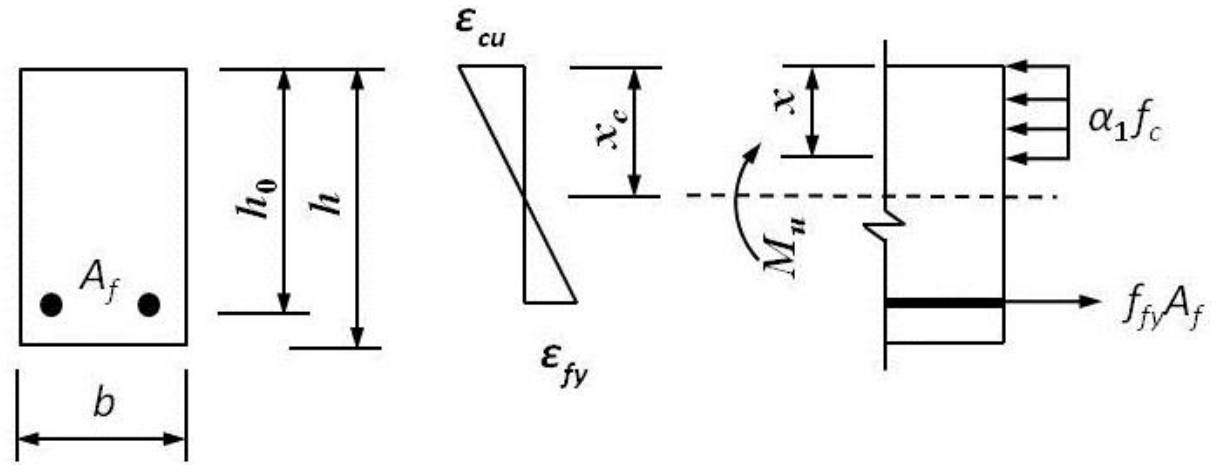

Fig. 15 Stress distribution over the beam's cross-section for balanced failure condition 


\section{Tables}

Table 1 Chemical compositions of fly ash and GGBFS (wt.\%)

\begin{tabular}{lll}
\hline Oxide & FA & GGBFS \\
\hline Silicon dioxide, $\mathrm{SiO}_{2}$ & 51.12 & 33.20 \\
Aluminium oxide, $\mathrm{Al}_{2} \mathrm{O}_{3}$ & 29.53 & 14.63 \\
Iron oxide, $\mathrm{Fe}_{2} \mathrm{O}_{3}$ & 5.57 & 0.34 \\
Calcium oxide, $\mathrm{CaO}$ & 2.99 & 37.13 \\
Potassium oxide, $\mathrm{K}_{2} \mathrm{O}$ & 2.38 & 0.33 \\
Sulphur trioxide, $\mathrm{SO}_{3}$ & 1.34 & 2.97 \\
Magnesium oxide, $\mathrm{MgO}$ & 1.03 & 9.18 \\
Sodium oxide, $\mathrm{Na}_{2} \mathrm{O}$ & 0.5 & 0.32 \\
Barium oxide, $\mathrm{BaO}$ & 0.06 & 0.36 \\
Others & 2.42 & 1.20 \\
Loss of ignition $(\mathrm{LOI})$ & 3.06 & 0.34 \\
\hline
\end{tabular}

Table 2 Particle size distribution of fine aggregates in inorganic polymer concrete

\begin{tabular}{ccc}
\hline Sieve size $(\mathrm{mm})$ & Total percentage retained $(\%)$ & Total percentage passing $(\%)$ \\
\hline 4.75 & 0 & 100 \\
2.36 & 13.74 & 86.26 \\
1.18 & 30.36 & 69.64 \\
0.60 & 49.50 & 50.50 \\
0.30 & 84.34 & 15.66 \\
0.15 & 96.98 & 3.02 \\
0.075 & 98.98 & 1.02 \\
\hline
\end{tabular}

Table 3 Particle size distribution of coarse aggregates in inorganic polymer concrete

\begin{tabular}{ccc}
\hline Sieve size $(\mathrm{mm})$ & Total percentage retained $(\%)$ & Total percentage passing $(\%)$ \\
\hline 20.00 & 0 & 100 \\
19.00 & 1.30 & 98.70 \\
16.00 & 16.66 & 83.34 \\
13.20 & 50.28 & 49.72 \\
9.50 & 87.62 & 12.38 \\
4.75 & 99.70 & 0.30 \\
\hline
\end{tabular}

Table 4 Mix proportion of raw materials in inorganic polymer concrete $\left(\mathrm{kg} / \mathrm{m}^{3}\right)$

\begin{tabular}{llllll}
\hline Specimen & Cement & $\begin{array}{l}\text { Inorganic } \\
\text { polymer } \\
\text { binder }\end{array}$ & Water & Fine aggregate & $\begin{array}{l}\text { Coarse } \\
\text { aggregate }\end{array}$ \\
\hline IPC & - & 425 & 153 & 615 & 1262 \\
\hline
\end{tabular}




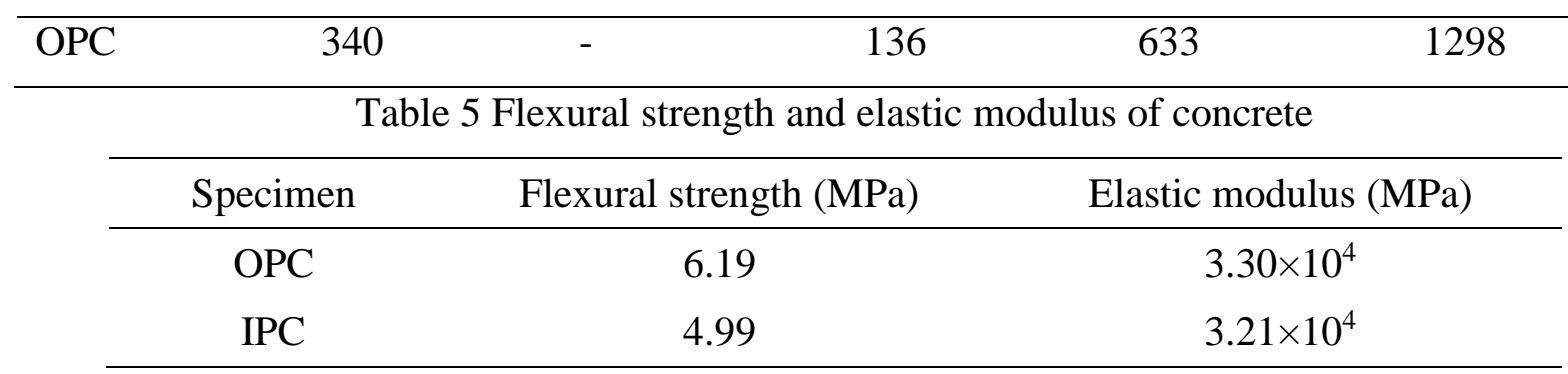

Table 6 Load and midspan deflection of concrete beams

\begin{tabular}{ccccccc}
\hline \multirow{2}{*}{ Beam } & \multicolumn{2}{c}{ Cracking } & \multicolumn{2}{c}{ Yielding } & \multicolumn{2}{c}{ Failure } \\
\cline { 2 - 7 } & Load $(\mathrm{kN})$ & Disp. $(\mathrm{mm})$ & Load $(\mathrm{kN})$ & Disp. $(\mathrm{mm})$ & Load $(\mathrm{kN})$ & Disp. $(\mathrm{mm})$ \\
\hline OPCB1 & 24 & 1.5 & 96 & 10.5 & 104 & \\
OPCB2 & 28 & 1.8 & 112 & 12.3 & 116 & 15.7 \\
IPCB1 & 22 & 5.3 & - & - & 92 & 40 \\
IPCB2 & 24 & 4.9 & - & - & 96 & 39 \\
\hline
\end{tabular}

